\title{
COOLEY'S ANAEMIA IN SINHALESE CHILDREN
}

\author{
BY \\ C. C. de SILVA and C. E. S. WEERATUNGE \\ From the Department of Paediatrics, University of Ceylon
}

(Received for Publication December 12, 1950)

Cooley's anaemia is a grave progressive anaemia occurring almost exclusively in children of Mediterranean stock. It is congenital and often familial (Cooley, 1949).

\section{Racial Distribution}

The first cases reported were all confined to those of Mediterranean stock, though Cooley denies a strictly racial incidence and believes that the mutation may occur in any race for some reason not yet discovered.

Nine cases have been reported from India, the last four being reported in the same paper by Chandra and Chaudhuri from Calcutta (1950). One case has been reported from China and three cases have been published occurring in Chinese of pure stock living in America (Foster, 1940; Gardner, 1947; Scott, 1947). Two cases in Negro children have been reported by Dameshek (1943) and Faber and Roth (1946).

This entity has now been identified in the Sinhalese, and is here reported for the first time from Ceylon. Chanmugam in his 'Anthropometry of the Sinhalese and Ceylon Tamils' (1949), basing his conclusions on 29 measurements and 15 indices, says that the Sinhalese and Tamils are similar to the Mediterranean races. He suggests that the Sinhalese probably originated from Baluchistan, some settling at Minicoy, and the others on the west coast of Ceylon. The brachycephaly of the Sinhalese, he suggests, may have originated in the north of the Hindukush or southern Europe. The Sinhalese are of the same moderate stature as the Mediterranean race which, according to Coon (1939), occupied an unbroken zone from Spain across the Straits of Gibraltar to Morocco and eastward. Shanklin (1946) found two varieties of the Mediterranean race living in the Transjordan and Syrian deserts. The Basques, who are of the same stature as the Sinhalese and Tamils, speak a language which, according to Coon, may have been brought from western Asia. From these observations of Coon,
Shanklin, and Chanmugam we may claim that the Sinhalese are of Mediterranean stock.

Cooley's anaemia falls into a group with a familial and racial entity distinct from the conglomeration of anaemias described by Von Jaksch. The appearance of these children is characteristic

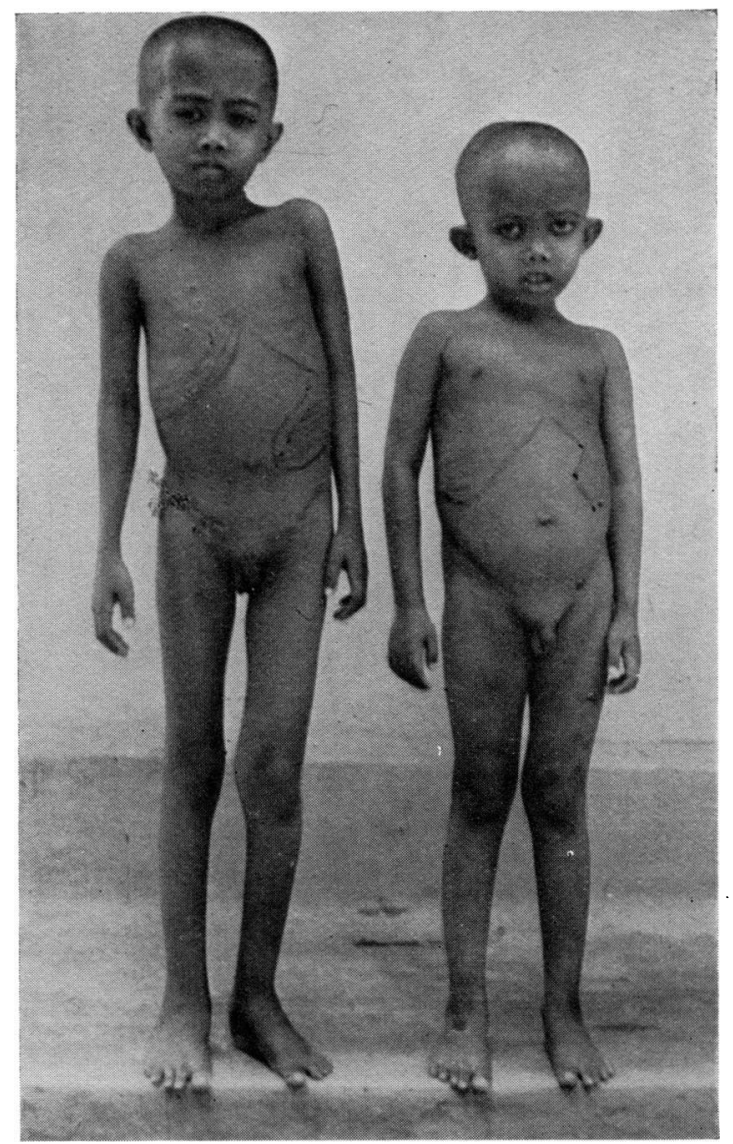

FIG. 1.-Photographs of cases 1 and 2 (brothers). Note the great facial resemblance, the high cheek bones and the flat noses which are not racial characteristics of the Sinhalese. The children have mongoloid facies. 


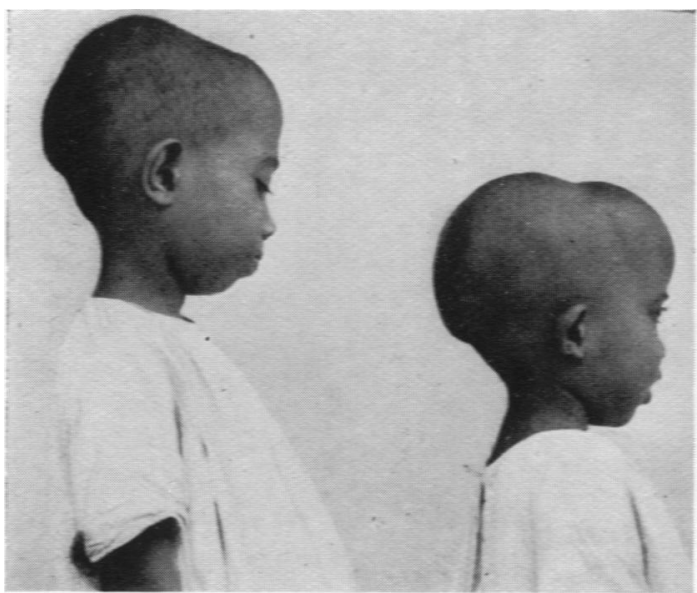

Fig. 2.-Photograph of cases 1 and 2 showing marked irregularity and bossing of skull.

(Figs. 1 and 2). They exhibit dwarfism to some degree and also mongoloid facies but these features are not always present. In any case they are not an early feature. The appearance of the skull is often characteristic in well developed cases. There is gross bossing giving the 'hot cross bun' appearance, and enlargement of the malar bones. The anaemia is usually severe. There is pallor, which produces a muddy-yellow complexion, but no true jaundice. The spleen is greatly enlarged and firm. The liver is enlarged to a lesser extent. The blood shows a hypochromic anaemia which may be macrocytic or microcytic, but the volume index is low. The blood picture shows marked poikilocytosis, anisocytosis, polychromasia, excessive fragmentation, nucleated cells, basophilic stippling and target cells, and high normoblast and reticulocyte counts. The white cell count is also moderately increased. The myelogram reveals a very high erythroid reaction. There may be more than a reversal of the normal ratio of myeloid and erythroid cells (Figs. 3-6).

\section{Case Histories}

Case No. 1. E.D., a Sinhalese boy aged 7 years, weighing $27 \mathrm{lb}$., height $3 \mathrm{ft}$. $5 \frac{1}{2}$ in., was admitted to the Lady Ridgeway Hospital, Colombo, on May 5, 1950, with a history of enlargement and deformity of the head for two years.

The lumps on the head appeared first as small nodules over the frontal region of the skull, one on each side, followed by two others on the parietal regions, which later extended to the occipital. While in hospital this patient developed an irregular pyrexia which lasted for over two weeks.

Two years before the present complaint the patient had had cedema of the whole body with fever for one month.
Both parents are alive and healthy. The patient was the third of five children, having two brothers and two sisters. The elder sister was pale and anaemic and showed a 'lump' over the posterior part of the skull. She had three normoblasts per 100 white blood corpuscles. The red cells were normal and did not show any anisocytosis, poikilocytosis, or target cells.

Blood films were made from 20 members of the family including parents, brothers and one sister, maternal aunts and uncles, maternal grandparents and several first cousins on both sides, but they revealed no abnormality except in the elder brother and sister.

On examination the patient was seen to be undernourished, pale, and anaemic. There was gross bossing of the skull. The bridge of the nose was depressed. The malar bones were prominent, the facies was mongoloid, the tongue was pale, moist, and clean. The pulse rate was 78 per minute; volume and tension were good.

The heart was within normal limits with normal sounds. The lungs were clear. The abdomen was distended but no free fluid was present. The spleen was enlarged to 6 in. below the costal margin with a smooth surface, firm consistency, and regular margin.

Blood analysis reports are set out in Table 1.

The $x$-ray appearances of the metacarpals and phalanges of the hand showed a mosaic pattern or lacing effect (Fig. 7). The transverse diameters of these bones

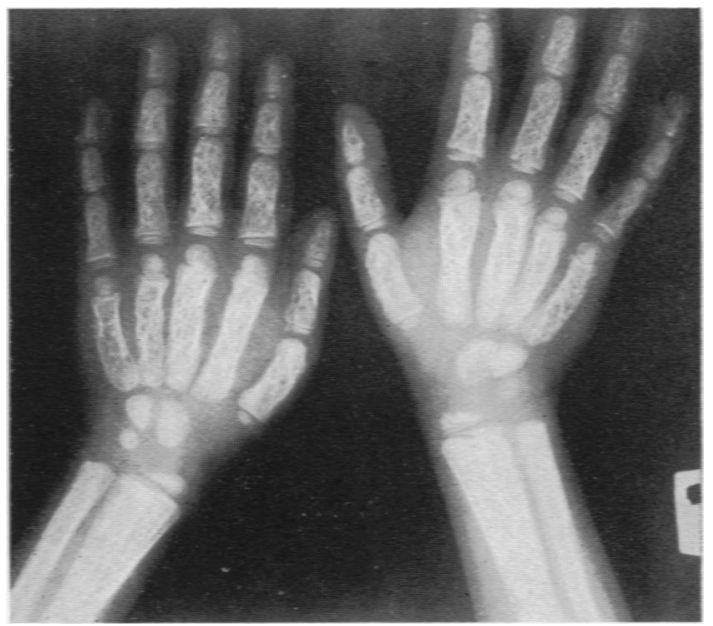

Fig. 7.-Phalanges and metacarpals show the lacing and widening effects and the irregular outline of the metacarpals.

were widened. These effects were present to a lesser degree in the metatarsals and phalanges of the foot. The bones of the skull showed an increase in width between the inner and outer tables, and the typical ' hair standing on end' appearance (Figs. 8 and 9).

Case No. 2. L.D., the elder brother of case 1, $10 \frac{1}{2}$ years old, was admitted on June 5,1950 . His weight was $41 \mathrm{lb}$., and height $3 \mathrm{ft} .10 \mathrm{in}$. This boy was rather dull and had taken no interest in his surroundings since his second year. He had a poor appetite for food. He 


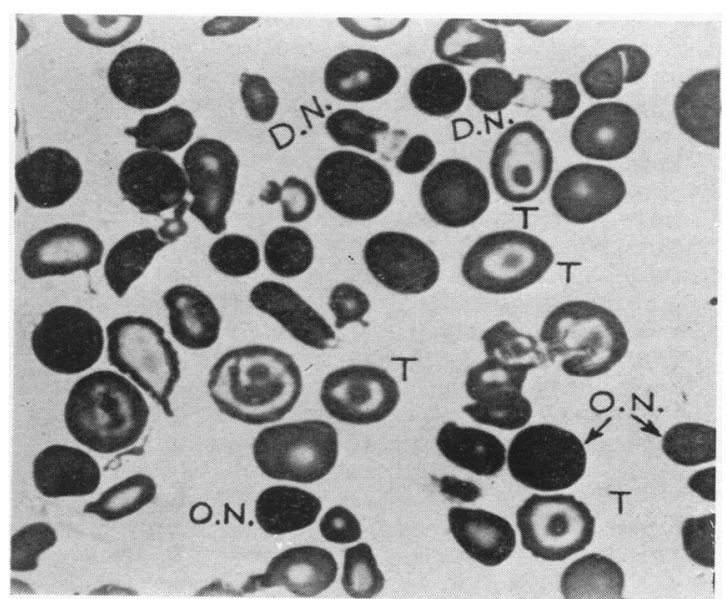

FIG. 3.

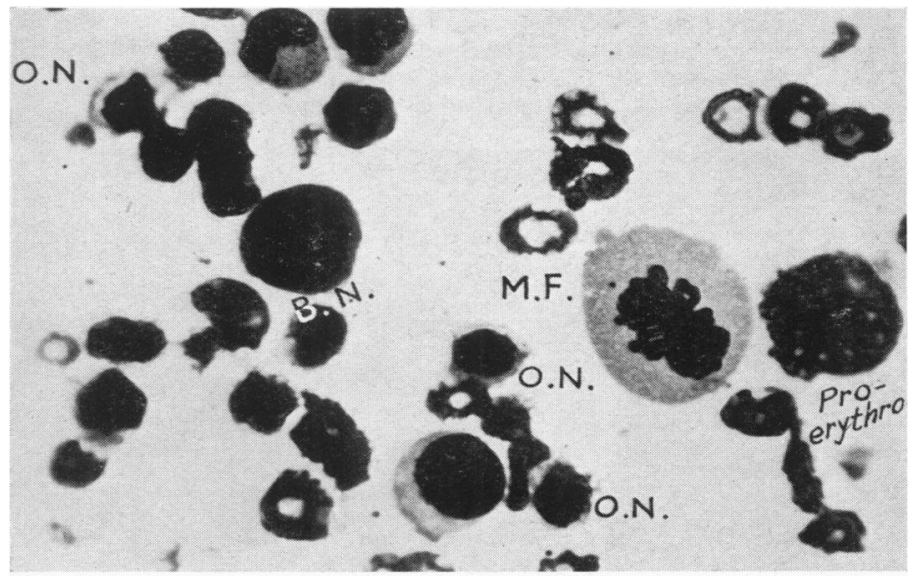

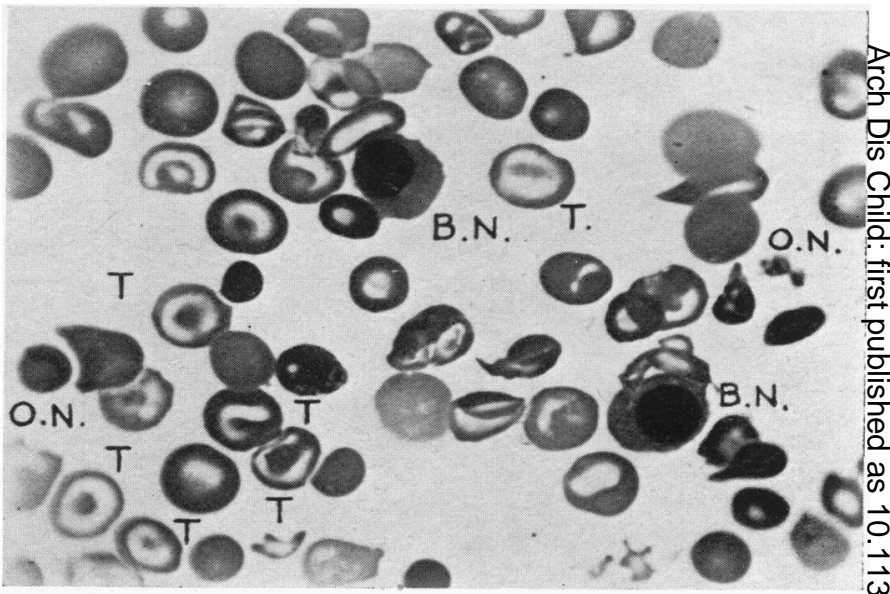

FIG. 4.

FIG. 3.-Blood film from case $1(\times 875)$ showing large number of target cells (T); ? dividing $N$ normoblast cells (D.N.) ; and orthochromic iv normoblasts (O.N.).

Fig. 4.-Blood film from case $3(\times 875)$ showing target cells (T); basophilic normoblasts (B.N.); $\subsetneq$ orthochromic normoblasts (O.N.).

FIG. 5.-Film of marrow from case $1(\times 875$. Mitotic figure (M.F.) is seen, also basophi normoblast (B.N.) and orthochromic normoblasts (O.N.).

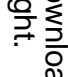

FIG. 6.-Marrow film from case $4(\times 875)$ 을 showing mitotic figure (M.F.), pro-erythroblasts, and orthochromic normoblasts (O.N.).

FIG. 5.

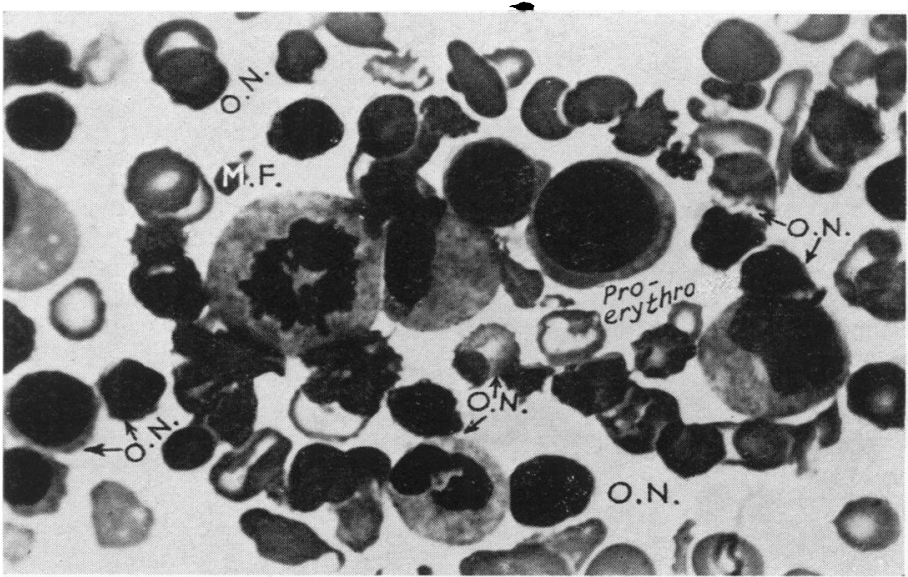

FIG. 6. 
was constantly falling ill with attacks of cough, cold, and fever. In 1948 he was admitted for oedema of the feet to the Lady Ridgeway Hospital, Colombo, where he was under treatment for one month and went away partially relieved. He had a limp following a fall a year earlier.

His family history is described in case No. 1 .

On examination the patient was seen to be pale, anaemic, and under-nourished. The malar bones were prominent. The facies was mongoloid. The feet were oedematous. The conjunctivae were pale. The tongue was pale, clean, and moist. The heart was within normal limits, with normal sounds. The lungs were clear. The abdomen was distended. The spleen was enlarged to the umbilicus, firm and not tender, with a smooth surface. The liver was enlarged to about 2 in. below the costal margin.

The $x$-ray appearances were similar to those of case 1, but less marked.

Blood findings are set out in Table 1.

Case No. 3. S.A., a Sinhalese boy aged $3 \frac{1}{2}$ months, was admitted to the Lady Ridgeway Hospital on March 13, 1950, with a lump in the abdomen and anaemia of one month's duration and a high, swinging temperature which continued till death. The boy was in good health for one month after birth.

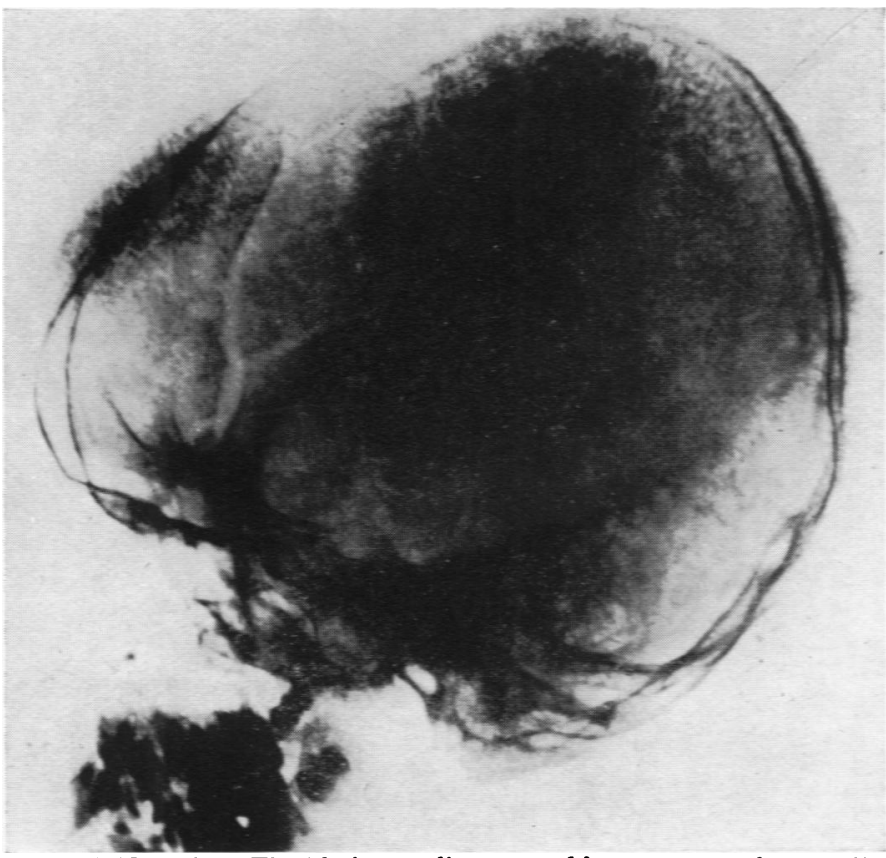

Fig. 9 (Case 2).-The ' hair standing on end ' appearance less well marked than in Fig. 8.
The patient was the youngest of five children. The parents were alive and healthy. The first three children were normal, but the fourth (boy) died of a similar complaint (a lump in the abdomen and anaemia) before he was a year old.

On examination the boy was apparently well nourished, weighing $10 \mathrm{lb}$. $12 \mathrm{oz}$. The skin was muddy-yellow. The heart and lungs showed nothing abnormal. The liver was enlarged to about $1 \frac{1}{2}$ in. below the costal margin. It was firm and not tender. The spleen was grossly enlarged extending to 1 in. above the left anterior-superior iliac spine. Nothing abnormal was discovered in the nervous system.

On radiography no bony changes were seen in the skull, metacarpals, or long bones. This child died during his fourth transfusion. No necropsy was allowed. The blood findings are set out in Table 1.

Case No. 4. D., a Sinhalese boy aged $1 \frac{1}{2}$ years, was admitted to the Lady Ridgeway Hospital on October 27, 1949 , for a lump in the abdomen and intermittent fever of one year's duration.

The boy was normal and healthy till the onset of the present illness.

He was the only child of normal and healthy parents.

The patient was undernourished, weighing $13 \mathrm{lb}$. $4 \mathrm{oz}$. He had a mongoloid 
facies and a 'hot cross bun' appearance of the skull. The skin was a muddy-yellow.

The heart and lungs showed no abnormality. The liver was not palpable below the costal margin. The spleen was enlarged down to the umbilicus. It was firm and not tender; the surface was smooth. The spleen varied a great deal in size during the time the child was in hospital. The inguinal, axillaty, and cervical glands were enlarged and shotty.

Radiographs showed that the parietal bones had the ' hair standing on end' appearance very slightly; otherwise the skull and metacarpal bones showed no abnormality.

The blood picture is seen in Table 1.

The child died during the fifth transfusion. No necropsy was allowed.

\section{Discussion}

We present four cases of Cooley's anaemia which were investigated. In addition there was a ? fifth case which could not be investigated fully as the parents refused admission to the hospital, although this patient showed the highest normoblast count of all in the peripheral blood (388 normoblasts per 100 W.B.C.s.). The spleen was grossly enlarged and he had the typical muddy-yellow complexion.

The bony changes shown in the radiographs of $ळ$ the metacarpal bones and the skull are present in $\overrightarrow{0}$ the cases which belong to an older age group or have suffered from the condition for some time. The youngest patient, aged $3 \frac{1}{2}$ months, showed no 
radiological signs of the disease process, but the typical blood changes were present. The splenomegaly in this case was noticed by the parents at the age of 1 month.

Once the diagnosis has been made the disease is slowly progressive. The younger the patient, the more rapid the progress, and the shorter therefore the period of survival. Growth is clearly retarded, as was shown in our cases 1 and 2, which we consider below average in height and weight. The peculiar mongoloid facies is probably due to marrow hyperplasia in the maxillary bones producing the high cheek-boned appearance. There is no slanting of the eyes or inner canthus present as in true mongoloid idiocy, though some writers claim that these are present in their cases (Cooley, 1949). The bossing of the skull, which produces the "hot cross bun' effect or the grotesque lumps on the frontal and parietal or occipital regions, is due to the same reasons. In Fig. 2 the photographs of cases 1 and 2 show a striking facial resemblance. This is present even in the unrelated patients. The peculiar skin colour is apparent even in the dark brown skin of the Sinhalese, which takes on a muddy-yellow tint and is quite different from the colour produced by any type of jaundice.

The most striking change in the peripheral blood is the great preponderance of nucleated red cells, especially mature and partly mature normoblasts. In addition there are large numbers of target cells and abnormal forms, shapes, and sizes of red cells. The enlarged spleen is usually the earliest sign. The changes in it are probably due to its function of breaking down and disposing of the end-products of the fragmented cells. Whipple (quoted by Cooley, 1922) suggests that the storage in the liver of the haemoglobin-forming substances, which the marrow is unable to use, accounts for the hepatic enlargement. Cooley is of the opinion that the bony changes are an indication of a primary progressive abnormality of the marrow, or hyperplasia, due to long continued over-stimulation, and the bony striae are the result of irritation.

Polychromasia and a high reticulocyte count were present in our cases. The urobilin in the urine was within normal limits and the icterus index and indirect Van den Bergh reaction were very slightly raised. Cooley believes that the excessive fragmentation and peculiar irregular deposition of haemoglobin in the cells are related to one another and indicative of abnormalities in the physico-chemical structure of the cells, which causes them to go to pieces rapidly in the circulation. The destruction by fragmentation is more extreme than in any other anaemia, and might well be the reason for the great marrow stimulation and hyperplasia. The presence of numerous target cells is very striking. These cells are not peculiar to any one anaemia. They are present in sickle cell anaemia and anaemias due to liver disease. We have also seen target cells in abundance in blood films from cases of severe hookworm anaemia. It is probably a result and not a cause of the disease process. Punctate basophilia is a prominent feature and is probably due to a defect in the structure of the corpuscle. The red cell fragility to solutions of saline is reduced in this condition, in contradistinction to the increased blood fragility in haemolytic icterus, but we did not always find the widened span.

Marrow. The marrow showed a wide variety of cells with a marked preponderance of the erythroid series, especially of the normoblasts, which ranged from $70 \%$ to $85 \%$ of the cells. Most of the normoblasts were polychromatophilic or orthochromic and not basophilic. The pro-erythroblasts were few in number and the others were of normal range. There were in addition quite a number of mitotic figures with fascinating shapes and sizes of nuclei. Target cells were also seen but were probably from the peripheral blood.

X-ray Findings. All the bones reflected the extreme marrow hyperplasia. In our cases the shafts of the long bones showed widening of the marrow cavity and marked trabeculation along their length. There was thinning of the cortex in parts. The trabeculation was best seen in the carpus and the phalanges, producing a beautiful picture of the mosaic pattern. Spontaneous fractures are said to occur in these bones but our cases showed no such evidence. The appearance of the skull is quite characteristic in cases of some duration. The bones of the vault are thickened and bossed, and later the striking 'hair standing on end' appearance or the 'golliwog' skull. This is due to a hyperplasia of marrow between the inner and outer tables of the skull. These changes are also seen in sickle-cell anaemia but the thinning of the cortices is not so noticeable.

Wintrobe (1946) refers to a minor form of this condition which he terms thalassaemia minor in contradistinction to thalassaemia major which is the classical form of the disease. The former, he states, is present in the blood relations, parents and other siblings, of the patient. We examined 20 blood films from near relatives and only in one sister did we find any deviation from the normal. There was no irregularity of the haemoglobin distribution and there were no target cells, poikilocytosis, or polychromasia. Chini and Malaguzzi Valeri (1949) claim that there is a decreased fragility to hypotonic salines in thalassaemia minor. We have not been able to investigate this. 
Nittis and Spiliopulos (1937) have suggested that this condition may be a peculiar form of malaria. None of our patients ever showed any malarial parasites in the blood. Their temperature charts were quite different to those of any type of malarial fever, but they were not given any anti-malarial remedies. Caminopetros (1938) claimed on the other hand that infecting his patients with malaria produced good results.

\section{Summary}

Four cases of Cooley's anaemia are reported from Ceylon in male Sinhalese children.

The two older patients showed marked radiological changes in the skull, long bones, and metacarpals and phalanges. The blood changes were typical.

Our thanks and acknowledgments are due to Dr. G. H. Cooray of the Department of Pathology, University of Ceylon, to Drs. Welikale and Jayamanne, of the X-ray Department of the General Hospital, Colombo, and to Messrs. G. Webster, Justin de Silva, A. S. Mahawatte and Vernon Jayawardena for technical help in preparing blood and marrow films and the photographs.

\section{REFERENCES}

Caminopetros, J. (1938). Ann. Méd., 43, 27.

Chandra, N. K., and Chaudhuri, K. C. (1950). Indian J. Paediatr., 18, 89.

Chanmugam (1949). Ceylon Journal of Science (section C), 4, Part 1, 1-18.

Chini, V., and Valeri, C. Malaguzzi (1949). Blood, 4, 989.

Cooley, T. B. (1949). In Brennemann's Practice of Pediatrics, vol. 3, ch. 16, pp. 54-66.

Coon, C. S. (1939). Quoted by Chanmugam. The Races of Mankind'. Pp. 39, 246, 293, 401, 404, 418, 431, 502.

Dameshek, W. (1943). Amer. J. med. Sci., Hagerstown, Maryland, U.S.A., 205, 643.

Faber, H. K., and Roth, B. M. (1946). J. Pediat.. 28,610 .

Foster, L. P. (1940). Amer. J. Dis. Child., 59, 828.

Gardner, L. B. (1947). J. Pediat., 31, 347.

Jaksch, R. von (1889). Wein klin Wschr., 2, 435, 456.

Nittis, S., and Spiliopulos, G. (1937). Amer. J. Dis. Child., 54, 60.

Scott, A. V. (1947). Chin. med. J., 65, 77.

Shanklin, W. M. (1946). Amer. J. phys. Anthrop., n.s.. 4, 323.

Wintrobe, M. M. (1946). 'Clinical Hematology, 2nd edit., pp. 564-574. London.

Whipple, G. H. Quoted by Cooley, T. B. (1922). Arch. intern. Med., 29, 711. 